\title{
Schizophrenia: from Epidemiology to Rehabilitation
}

\author{
Gioia Mura ${ }^{1}$, Donatella Rita Petretto ${ }^{2 *}$, Krishna M. Bhat $^{3}$ and Mauro Giovanni Carta ${ }^{1}$ \\ ${ }^{I}$ Consultation Liaison Psychiatric Unit at the University Hospital of Cagliari, University of Cagliari and AOU \\ Cagliari - Italy \\ ${ }^{2}$ Department of Education, Psychology, Philosophy, University of Cagliari Loc. Sa Duchessa 09127 Cagliari, Italy \\ ${ }^{3}$ University of Texas Medical Branch, Galveston, Texas, USA
}

\begin{abstract}
Purpose/Objective: We discuss recent evidences about schizophrenia (frequency, onset, course, risk factors and genetics) and their influences to some epidemiological myths about schizophrenia diffuse between psychiatric and psychopathology clinicians. The scope is to evaluate if the new acquisitions may change the rehabilitation approaches to schizophrenia modifying the balance about the neurodevelopmental hypothesis of schizophrenia accepting that the cognitive deficits are produced by errors during the normal development of the brain (neurodevelopmental hypothesis) that remains stable in the course of illness and the neurodegenerative hypothesis according of which they derived from a degenerative process that goes on inexorably.

Research Method/Design: A review of the literature about epidemiology of schizophrenia has been performed and the contributions of some of these evidence to neurodevelopmental hypothesis and to rehabilitation has been described.

Results: It cannot be definitively concluded for or against the neurodevelopmental or degenerative hypothesis, but efforts in understanding basis of schizophrenia must go on. Until now, rehabilitation programs are based on the vulnerabilitystress model: supposing an early deficit that go on stable during the life under favorable circumstances. So, rehabilitation approaches (as neuro-cognitive approaches, social skill training, cognitive-emotional training) are focused on the individual and micro-group coping skills, aiming to help people with schizophrenia to cope with environmental stress factors.

Conclusions/Implications: Coping of cognitive deficits in schizophrenia may represents the starting-point for further research on schizophrenia, cohort studies and randomized trials are necessary to defined the range of effectiveness and the outcome of the treatments.
\end{abstract}

Keywords: Schizophrenia, functioning, epidemiology, genetics, etiology.

\section{INTRODUCTION}

Aim of the review is to understand whether epidemiological new findings may influences theories that support the rehabilitation approaches to schizophrenia. Indeed, 100 years later the Kraepelin's distinction between affective disorders and schizophrenia (dementia praecox), psychiatric research emphasizes the organic etiology of psychosis, in terms of genetic vulnerability, pathological and functional brain alterations. However, even if it's generally accepted that in schizophrenia there may be a cognitive deficit, it's not clear if this impairment is produced by errors during the normal development of the brain (neurodevelopmental hypothesis) that remains stable in the course of illness, or if it is derived from a degenerative process (neurodegenerative hypothesis) that goes on inexorably.

We'll discuss recent evidences on epidemiology of schizophrenia (about frequency, onset, course, risk factors

*Address correspondence to this author at the Department of Education, Psychology, Philosophy, University of Cagliari, Cagliari Loc. Sa Duchessa 09127 Cagliari, Italy; Tel: 0039070/6757501, 00393286942727;

Fax: 0039070274778,0039070291204; E-mail: drpetretto@unica.it and genetics), and their influences to some epidemiological myths and to rehabilitation approaches.

\section{HISTORICAL OVERVIEW}

We can distinguish three types of studies that have been carried out over the years: 1) the early 'historical' studies conducted with key informants in the general population or on institutional statistics without standardized diagnosis; 2) the surveys conducted into small communities using fixed diagnostic criteria (that were often difficult to compare and to extend); 3) the most recent researches conducted with standardized descriptive diagnosis, sampling methods and (semi-) structured interview tools to assure reliability.

In the $1970^{\text {th }}$, the key turning point in the history of psychiatric epidemiology was the US / UK project sponsored by WHO [1], aiming to highlight the strong discrepancy in diagnosis of schizophrenia between London's and New York's institutional statistics. Recording interviews and crossing diagnosis with common defined criteria, diagnosis of schizophrenia became reliable $[2,3]$.

The introduction of common diagnostic criteria on schizophrenia allowed the who International Pilot Study on Schizophrenia. This survey stated that symptoms of schizo- 
phrenia are found around the world in many cultures and that profiles of schizophrenic pictures look similar in different cultural backgrounds [4].

In the $70^{\text {th }}$, surveys on affective disorders, hysteria and anxiety indicated in a balanced way that others disorders than schizophrenia seem to be more culturally sensitive, at least as different clinical presentation. In some way an idea that schizophrenia was quite similar in all countries may be counter (as biologic entity) with other less biological entities present in the common professional conscience.

In the middle $80^{\text {th }}$, the concept of a worldwide dimension of schizophrenia was reinforced by results of the WHO research "Determinants of Outcome" [5]. Those findings seemed to indicate a stable incidence rate of schizophrenia around the world. All six sites in high mean income countries showed a really stable annual incidence rate, except the Chandīgarh site in India showing little higher incidence rate, around 0.30 [6].

\section{FREQUENCE AND RISK FACTORS}

\section{Prevalence and Incidence: the Myth of the Stability}

Since today, most psychiatric handbooks state that schizophrenia has a stable frequency around the world. However, a recent review shows that schizophrenia is not distributed equally across cultures and countries. From 132 core studies, 15 migrant studies, and 41 studies based on other special groups, the median values per 1,000 persons for the distributions for point and lifetime prevalence were 4.5 and 4.0, with a very large range in different studies [7]. Prevalence rate may be influenced by different length of disease course in different countries, so it may not be conclusive concerning the stability of incidence.

But the same review and others four in the last two years indicate unequivocally that the incidence rate of schizophrenia varies from different countries and cultures with a large range.

Considering the different published papers on incidence in schizophrenia after 1985, the lowest rates were reported in Vancouver and in Oxfordshire in UK (both with less 0.1 per $1,000)$, while the highest were reported in Madras with 0.58 and Bavaria with 0.48 [6].

\section{Gender Risk}

Another possible epidemiological myth concerns the gender risk and the difference of disease course by sex.

It is reported in many psychiatric textbooks that men and women are affected equally by schizophrenia. Recent metaanalyses of third generation epidemiological studies have clarified that this is not the case. For every three males with schizophrenia there are two females with the disease $[8,9]$.

One reason of this "belief" may due to difference that was thought to exist between schizophrenia and affective psychosis in gender risk: one simple and stable concept was that male to female ratio in schizophrenia risk is $1 / 1$, while in affective psychosis is $1 / 2$. However, recent data highlighted that the male to female ratio is $1.2 / 1$ also in bipolar disorders, remaining $1 / 2.5$ only in major depressive disorder.
Prenatal, Perinatal and Complications of Normal Brain Development for the Pathogenesis of Schizophrenia. Childhood Risk Factors

Many evidences support hypothesis that schizophrenia could be a neuro-developmental disease caused from a brain damage occurring in early phases of life, that interferes with the normal developmental events [10-12]: 1) seasonality of birth; 2) prenatal exposition to flu viruses and Toxoplasma gondii; 3) birth complications; 4) brain abnormalities on neuroimaging tools.

For a long time it has been known that individuals with schizophrenia are more likely to be born in the winter. Consistent data supporting this finding results from studies in Northern and Southern Hemispheres [13]. Despite that relative risk is small, on the order of 5-8\% increase for those born in the winter versus summer, corresponding to a relative risk of 1.05-1.08, this datum has been replicated many times. One possible explanation is that mother is passing through the second trimester of her pregnancy in the height of flu season, and it is that infections during that period raise risk for schizophrenia in offspring. Another explanation was offered by a recent study carried out in a country with minimal seasonal weather change [14]. The fact that seasonality effect was found in patients with schizophrenia of a group likely to have increased genetic susceptibility suggests geneenvironment interaction, perhaps in terms of epistasis between exogenous factors and maternal-inherited genes.

Recent data emphasize contribution of prenatal exposition to flu virus $A$ and $B$ in determining significant reduction of cognitive performances in children who will develop psychosis in adulthood [15]. Those data suggests a role of environmental factors that may act on fetal brain determining a loss of cognitive performances soon before onset of psychosis.

A meta-analytic review on birth complications acting on schizophrenia risk categorizes different types of birth complications involving I) complications of pregnancy (bleeding, diabetes, Rhesus incompatibility, preeclampsia), II) abnormal fetal growth and development (low birthweight, congenital malformations, reduced head circumference), and III) complications of delivery (uterine atony, asphyxia, emergency Cesarean section); overall risk for developing schizophrenia associated with obstetric complications were generally modest, less that 2.0 [16]. Nevertheless, recent data suggest only a modest association between prematurity, hypoxia, maternal infections and maternal behaviors and risk of the later development of schizophrenia after adjusting for a number of possible confounding factors [17].

Moreover, it has been emphasize that adverse events acting during pregnancy or delivery are associated with an increased risk to develop psychotic-like non-clinical symptoms (PLIKS) that regards 15\% of population. Such an association is particularly relevant in case of maternal infectious diseases during pregnancy, gestational diabetes, need of neonatal cardio-pulmonary resuscitation, Apgard's index less than 5 [18].

Researches on infectious agents as possible cause of schizophrenia has become prominent in the past decade. Toxoplasma gondii has emerged as a prime candidate for a 
variety of reasons: I) individuals with schizophrenia, compared to controls, have been reported to have higher prevalence of antibodies to Toxoplasma gondii; II) some individuals with adult toxoplasmosis develop psychotic symptoms similar to those of schizophrenia; III) Toxoplasma has been shown to induce elevated levels of dopamine in experimentally infected animals; and IV) studies have shown that individuals with schizophrenia, compared to controls, have had greater exposure to cats in childhood [19-22].

Taken together, most studies seem to delineate that exogenous factors acting on brain structure during its developmental phase play an important role in etiopathogenetic of schizophrenia.

\section{Low IQ}

Considering childhood developmental abnormalities, many long-term follow-up studies, both retrospective and prospective, suggest a variety of signs, symptoms, conditions and behaviors associated with raised risk for schizophrenia, but no study is strong enough as to be useful in prediction. Earlier report on high risk groups showed that offspring of schizophrenic parents were more likely to have lower IQ, poor attention skills, thought disorder-like symptoms, poor social adjustment and psychiatric symptoms compared to offspring of controls [23]. Although several concerns have been raised regarding generalization of high risk findings to non-familial forms of schizophrenia, recent longitudinal studies provided evidence that individuals with schizophrenia differ from their peers even in early childhood in several developmental markers, such as age of attaining developmental milestones, levels of cognitive functioning, educational achievement, neurological and motor development, social competence and psychological disturbances. Prospectively collected data from a birth cohort in New Zealand [24] showed that schizophrenic subjects should have suffered significant deficit in neuro-motoric, linguistic and cognitive development in the first decade of their lives. The authors say that the compelling evidence linking an array of childhood developmental abnormalities and schizophrenia echoes with the hypothesis that schizophrenia is a neurodevelopmental disorder.

Evidence also suggests that the association between low IQ is specific to schizophrenia as it was not found in bipolar disorder.

\section{Paternal Age}

First indication on a role of parental age was based upon the family background data of 1000 patients in the Ontario Hospital, Canada. Gregory [25] reported that parents of patients with schizophrenia were, on average, 2-3 years older than those of the general population.

More recently, several population-based epidemiological studies in Denmark [26], Israel [27], Sweden [28], France [29] and the United States [30] have provided stronger evidence on role of paternal age in schizophrenia. A populationbased birth cohort study found that relative risk of schizophrenia is 2.96 in the group of fathers aged 55 or above at the time of offspring birth; once paternal age was accounted for statistically, maternal age no longer was a significant predictor of schizophrenia [31].
Current population-based cohort research tends to support that advancing paternal age-related increased risk of schizophrenia only appears significant among those without family history. Genetic mechanisms that could explain these association are been proposed, including accumulation of de novo mutations in paternal germ cells, trinucleotide repeats expansions, and alterations in genetic imprinting of one or several genes involved in neurodevelopment [31-33]. Using k-means clustering analysis, Lee et al. emphasize that paternal age related schizophrenia (PARS) cases differ phenotypically from other patients with schizophrenia in features including discrepancy in verbal and performance intelligence and, in female, in early age at onset [34].

Although definite biological explanation has not yet been done to explain the role of paternal-age, the findings strongly point toward biologically complex transmitted factor acting in developing embryonic nervous system.

\section{Autoimmune Diseases}

The role of neuro-inflammation in schizophrenia has been an issue for long time. Association between schizophrenia and various inflammatory-autoimmune diseases has been reported in epidemiological surveys.

Several studies have shown that individuals with schizophrenia are somehow less likely to have rheumatoid arthritis [35]. However, while it could be that medications for schizophrenia are protective for rheumatoid arthritis in some unknown way, several studies were conducted prior to era of neuroleptic medications. A possible explanation is that a single gene raises risk for one disorder and protects for the other. It has been reported that mothers of individuals with schizophrenia have lower risk for rheumatoid arthritis, but the study is questionable for the small sample size.

Other immune disorders have been linked to schizophrenia, particularly autoimmune thyroiditis and celiac disease $[36,37]$. A study from the Danish population registers, reported that persons whose parents had celiac disease were three times as likely to have schizophrenia [38]. Celiac disease is characterized by immune reaction to wheat gluten. One possible explanation is that increased permeability of intestine, raising level of antigen exposure, could increase risk of autoimmune response to brain components. It is also possible that gluten proteins are broken down into psychoactive peptides.

Various data suggest apparent abnormalities of immune system in schizophrenia, but it is not clear whether such those alterations are causal or merely consequent to schizophrenia itself or to the common treatments used in the disease. It can be hypothesized that a general weakness of immune system increased risk determined either by infections or by autoimmune disorders reported in individuals affected with schizophrenia [39].

Recently, a genome-wide microarray study in postmortem brains of schizophrenia patients has explored expression profiling of immune-modulatory genes, showing that 23 genes were significantly down-regulated in Brodmann area 22 of left superior temporal cortex, supporting the hypothesis that in schizophrenia immune-related genes modifies synaptic functions and stability in a selected corti- 
cal area [40]. This study may offer an explanation for findings showing association between autoimmune disorders and schizophrenia and, considering the progressive nature of autoimmune diseases, seem to indicate that schizophrenia may arises from a progressive process of neurodegeneration. However, the study does not clarify if the observed downregulation of immunomodulatory genes reflects secondary (or even terminal) neural changes to a primary immune response.

\section{Migration}

The hypothesis that migration is a risk factor for schizophrenia has been accepted by many authors; however, there are not yet concordant theories about the role played by migration on development of the disease.

The first epidemiological evaluation of psychiatric disorders in immigrants dates back to more than seventy years ago [41], but the results obtained were limited due to methodological problems, such as the absence of standardized diagnostic criteria, structured interviews, and to investigations being carried out on the general population and not only on subjects who had been seen by psychiatrists. Moreover, it is impossible to consider "immigrants" as a homogeneous group concerning the risk of psychiatric disorders, due to variables as motivation to migration, distance for the host culture, ability to develop mediating structures, and legal (or illegal) residential status [42].

In Europe, the issue about increasing risk of schizophrenia in immigrants was studied by several authors. The interest in migration as putative risk factor for schizophrenia was generated by data showing that persons of AfricanCaribbean origin migrating in UK have an incidence rate 2.5-14.6-fold higher compared to native people [43]. Following this initial report, high incidence rates have also been reported for persons of Surinamese, hospital admission, found that five and second generation immigrants have an increased risk for severe psychiatric disorders compared to natives. The role of ethnic factors in the risk of Dutch Antillean and Moroccan background migrating in the Netherlands $[44,45]$ and for all migrants in Denmark [46]. It can be underlined that incidence peak appears 10-12 years after migration and that rate of schizophrenia is high also in the secondgeneration migrants [47]. In one of the first longitudinal studies, Hjern and colleagues [48], analyzed incidence rates of first schizophrenia was underlined in a study carried out in Malmo [49], which confirmed that migrants had increased risk for schizophrenia compared to natives, but the risk was markedly increased in immigrants of East Africa.

Various hypotheses have been formulated in order to explain role of migration in development of the disease, but at present there are no firm data in favor of one specific theory.

It has been believed that the rate of schizophrenia was high in original Countries of migrants. There are few studies regarding rate of schizophrenia in the original Countries before 1990 [50]; after this period, the Determinants of Outcome in Severe Mental Illness (DOSMD) study demonstrated that in the original Countries rate of schizophrenia was less than in migrating populations, suggesting that biological vulnerability to stress is not sufficient to explain the high rate of schizophrenia in these social groups [51].
According to the "selective migration" theory, individuals affected with schizophrenia are more predisposed to migrate [41]. Despite this hypothesis is fascinating, it conflicts with data from meta-analyses on population-based studies, that show that risk of schizophrenia was higher in secondthan in first-generation migrants [52]. Moreover, migration itself and the consequent stress may be difficult to be tolerated in individual affected with schizophrenia [53]. Together, it is difficult to refute the hypothesis that a single biological factor can adequately explain increased risk for schizophrenia in migrants. Socio-environmental elements, acting in concert with genetic factors, may contribute to explain the particular liability of migrant populations to the disease [54].

In the meta-analysis of Cantor-Graae and Selten [52], migrants whose skin color is considerably darker than the background population were reported to have a relative risk of schizophrenia of 4.8. Migrants in general, and specifically whose with dark skin, may be more subject to the effect of poverty and discrimination, particularly in countries where racism is present either individually or institutionally. However, a higher risk for schizophrenia has not been found in Turkish migrants to the Netherlands, despite the fact that Turkish migrants had lower socioeconomic conditions than Surinamese migrants, whose relative risk is high [44, 45]. It has been demonstrated that risk of develop schizophrenia increases when size of migrants in the country of migration is small, while risk is lower in great communities of migrants belonging from the same country [55]. These data reinforce the hypothesis that isolation and lack of social support are determinant factors in the pathogenesis of schizophrenia [56].

However, it can be hypothesized that migrants have a genetic susceptibility to environmental factors present in countries of migration (such as pollution, pathogens, allergens, etc.), absent or rare in the original countries. This hypothesis can put together genetic theory and the role of environmental stressors [57].

Misdiagnosis can explain the high incidence rate of schizophrenia observed in African-Caribbean people; however, misdiagnosis cannot be the unique explanation for this finding. Diagnostic criteria and standard definition of schizophrenia reduce diagnostic errors; thus, using the same criteria also in original countries an overestimate of the disease should be observed $[58,59]$.

In conclusion, there is no agreement between various authors and the role of migration is still an enigma: it is likely that liability to schizophrenia in migrants may arise from biological factors acting in individuals/ethnic groups genetically predisposed to the disease. These findings could indicate a mixed action of a precocious inherited neurodevelopmental alterations and subsequent environmentaldriven neurodegenerative processes in schizophrenia pathogenesis.

\section{Addiction}

Many abuse drugs have been related to onset of schizophrenia. Use of D-amphetamine and of cannabis (both acting on dopaminergic system) during adolescence can contribute to subsequent onset of schizophrenia or to an increase of 
psychotic symptoms in schizophrenic individuals. However, abuse drugs such as lysergic acid diethylamide (LSD) and psilocybin, acting on serotoninergic system, or dissociative anesthetics, such as ketamine and phencyclidine, acting on glutamate-related system, can equally cause psychotic symptoms. This suggests that dopaminergic imbalance cannot be the only responsible of schizophrenia development, as demonstrated by antipsychotic action of drugs commonly used in treatment of schizophrenia, as clozapine and olanzapine, both having antagonistic 5HT2 action higher compared to D2 action.

Moreover, there are numerous case-control studies showing that persons with schizophrenia are more likely to have taken, or be using, cannabis [60]. Recently there have been prospective studies in Sweden [61], the Netherlands [62], New Zealand [63], and Israel [64] showing higher risk, ranging from 2 to as high as 25 , for cannabis smokers. It could be that individuals in the premorbid phase of schizophrenia are responding to initial, mild symptoms of schizophrenia by using drugs. On the other hand, it could be that cannabis precipitates, or even causes, an episode of schizophrenia.

This concept may be explained by a recent cohort study on patients indicating an association with a polymorphism of COMT, involved in dopamine regulation and related to negative symptoms, associated with drug use and young age at onset [65].

Together, data on drug abuse do not aid in clarify if schizophrenia arises from a neurodevelopmental or a neurodegenerative process; however, carriers of several genetic variants taking substances acting on neurotransmitters may be a population particularly prone to schizophrenia. Identification trough biomarkers of such persons can aid in understanding biological relevant pathways of the disease.

\section{Urbanicity}

In the 1930's Farris and Dunham [66] showed that, while the addresses of first admissions for manic depressive illness were distributed more or less randomly throughout Chicago, admissions for schizophrenia tended to come from the center of the city, with decreasing rates as one moves outward into zones of transition, working class, and family. This finding, and other similar findings, was interpreted as due to the selection into the city of individuals who would develop schizophrenia.

Later studies from Europe provides persuasive evidence that risk for schizophrenia increases with urban birth and/or upbringing, especially among males. This studies concern the meta-analysis of Kelly about DSMIII incidence studies and are designed in a strictly prospective way [67], with the cohort defined in late adolescence, well prior to onset, or even at birth. Yet, urbanicity exerts its influence only in childhood and adolescence, not in adulthood (it may indicate that it's necessary a long, continuous or repeated exposure at the environmental factors) $[68,69]$ and the association between urbanicity and schizophrenia is higher in the more recent cohort studies (so, the impact of urbanicity increases with time) $[70,71]$. The mechanism of association is unclear, but it may be related to biological or social/environmental factors or both, acting considerably before psychotic symptoms manifest. There are different potential candidates, in- cluding air pollution, cannabis and social exclusion [72]. Urbanicity may have a synergistic effect with genetic vulnerability [73]. Future researches are likely to focus on the relationship between urbanicity and neural aberrant development to explain the possibility of rural protective factors.

\section{Social Class}

There are two hypotheses trying to explaining the strong association observed between low social class and schizophrenia. According to the first one, poor environmental conditions of underdeveloped areas, such as infectious agents, unemployment, poor quality of maternal and obstetrician care, psychosocial stress, can be breaking factors for disease onset.

Second hypothesis, now more quoted, is called the "selection-drift hypothesis". It focuses on the high morbility rate observed in poor economic groups, resulting from social drift process as consequence of low social and working level due to the progressive and deteriorating nature of schizophrenia [74]. This process, together with larger frequency of schizophrenia in following generations, could explain social selection toward bottom and thus the presence of high number of affected individuals in the more poor socio-economic classes. Moreover, decline of performances in job and employment was reported to occur after diagnosis [75], related to the difficult to return to previous pre-morbidity functional conditions.

Apparently, these data point towards a role of degenerative process driven by socioeconomics factors as determinant of schizophrenia. However, well-known data from child psychology studies have clearly demonstrated that poverty, malnutrition, poor maternal and obstetrician care are key determinants in the proper neural development of child.

\section{Genetics}

Schizophrenia is considered a complex genetic disorder, resulting from a combined effect of environmental factors and more genes, each with small effect on the individual's phenotype. The main foundation for the search of molecular genetic risk arises from the twin and adoption studies. Genetic weight in schizophrenia, like in other complex disorder, starts from familial studies establishing the relative risk observed in relatives of affected compared to the risk observed in general population, called $\lambda$; the relative risk of siblings having a proband with the illness is called $\lambda_{\mathrm{s}}$. This value is about 10 in schizophrenia. It is common observation in complex diseases that the relative risk to a relative of an affected proband decays much more rapidly than the proportion of genes shared between them. However, the majority of schizophrenic cases are sporadic, due to the polygenic inheritance model: for a disease with a prevalence of $1 \%$ and $90 \%$ heritability, more sporadic than familial cases are expected [76].

Inheritance of the disease is confirmed by incidence and prevalence studies in monozygotic and dizygotic twins of schizophrenic patients. These studies demonstrate $60-70 \%$ of concordance in monozygotic twins, while concordance rate in dizygotic twins is not different from concordance observed in siblings $[77,78]$. The risk of schizophrenia is similar for offspring of both affected and unaffected monozy- 
gotic twins, suggesting an inheritable genetic background in risk of schizophrenia without expressing the disease $[79,80]$. These data, together with lack of total concordance in monozygotic twins, indicates that epigenetic or not-shared environmental factors, (or both), play a role in pathogenesis of the disease. Studies on adopted "high risk" subjects (as offspring of schizophrenic mothers) demonstrated that to grow up in an adoptive family do not reduce risk to develop the disease [81]. Concordance rate in twins grown up apart is similar to that found in couples of twins grown up together.

Candidate gene studies, which focus on genes potentially involved in a disease, have been a key approach to the genetic of schizophrenia. However, results of these studies are often confusing and no gene has unequivocally been implicated. Candidate gene studies explore linkage or association between the disease and several markers of genes known to codify proteins involved in mechanisms hypothesized in etiopathogenetic of the disorder. Hyperactive dopaminergic signal transduction in the central nervous system has been suggested in the pathophysiology of schizophrenia (dopamine hypothesis). Thus, several studies focused on genes coding for dopamine receptors. The Ser311Cys polymorphism of the dopamine $\mathrm{D}_{2}$-receptor gene has been associated with schizophrenia, particularly in patients without negative symptoms and the association was confirmed by three metaanalyses over 20 published studies [82].

Further applications of genetic research in comprehension of schizophrenia come from data on functional polymorphism Val108 /105 Met of COMT gene. The Val/Met polymorphism results respectively in high and low activity form of COMT, a catabolic enzyme involved in the degradation of a number of bioactive molecules, including dopamine. COMT gene, located in 22q11 chromosome, when deleted results in a complex syndrome that includes schizophrenia. The Val/Met polymorphism has become the most widely studied polymorphism in psychiatry, with data for and against the involvement of COMT in schizophrenia [83]. Some data suggest that the Val allele of COMT, increasing dopamine catabolism, reduces prefrontal cortex physiological activity and cognitive performances [84]. Moreover, according to a recent study, Val158Met COMT polymorphism could interact with use of cannabis in modulating risk to develop the disorder [85].

Large genome-wide linkage studies, mainly performed in the last 10 years, resulted in evidence of linkage in various chromosomal regions, as at 8p23.3-p21.2 and 11p13.1-q14.1 [86], at 18p11.32, 6 and 14 [87]. Some recent studies of association and linkage in schizophrenic populations emphasize several susceptibility genes, focusing on loci at $8 \mathrm{p}$ and $22 q$ chromosomes $[88,89]$. In total, 12 chromosomal regions containing 2181 known genes and 9 specific genes involved in etiology of schizophrenia have been reported. Biological markers related to variations/polymorphisms of such genes include variation in normal expression of proteins involved in neuronal and glial precocious migration, in nervous cell proliferation, in axonal growth, in synaptogenesis and in apoptosis. However, despite the high number of genes involved, up to now there is not univocal and replicable association in all studies.
The completion of Human Genome Project and the "HapMap" project led to genome-wide scans based on hundreds of thousands of single nucleotide polymorphisms (SNP), that are common genetic variants in the human populations. All findings are "data-driven" rather than "hypothesis-driven", as in the candidate-gene approach, and required many thousands samples and powerful statistical methods. These studies provided molecular evidence for a substantial polygenic component to the risk of psychiatric diseases involving thousands of common alleles, each with very small effect. A meta-analysis of results from the International Schizophrenia Consortium (ISC) compared the genome wide association study (GWAS) method to the hypothesis-driven candidate genes approach, showing that GWAS had $89 \%$ of power to detect genetic effects [90]. Collectively, ICS concluded that thousands of common polygenic variants with very small individual effects explain about one-third of the total variation in genetic liability to schizophrenia [91]. A recent large GWAS study reported genetic variations in a region on chromosome 11 , containing several candidate genes. Interestingly, in a subsequent imaging study, the authors found that healthy carriers of the risk allele showed altered activation in the cingulated cortex during a cognitive control task [92].

The candidate approach and the GWAS method are not mutually exclusive. Indeed, using a custom-array of 1,536 SNPs to interrogate 94 candidate genes in over 500 subjects, an association with endophenotypes was observed for 46 genes of potential functional significance and supporting a role for glutamate signaling in susceptibility to schizophrenia [93]. Using SNP-based linkage scan strong evidence for linkage in a region of chromosome 8p21 was showed [94], confirmed by another study based on linkage and familybased association and replicated with an independent casecontrol association study [95]. Other studies focused on copy number variants (CNVs) that are stretches of genomic deletions and duplications likely to have larger phenotypic effect than SNPs. A recent study evaluated previously reported association with CNVs found in the Molecular Genetics of Schizophrenia study. Combined with other data sets, the analysis confirmed deletions in five previously reported regions, including 22q11.2 deletion, and found new evidence for other CNVs [96].

It is conceivable that mutations associated with schizophrenia are different in small isolated populations and large outbred populations. In a pilot study carried out on a small sample in Sardinia [97], one of the authors of this report founded a genotype pattern (rs1360382 on chromosome 9 and rs1303 on chromosome 14) that was highly predictive of schizophrenia, while it was not implicated in none of the recently published large studies [98, 99].

Despite genetic discoveries accumulate, delineation of biological pathways involved in pathophysiology of schizophrenia and consequent development of new therapies is still in its infancy. Together with the application of new tools, insight in mechanism involved in gene-gene interaction and in environmental impact on gene expression (epigenetics) (as exploration of methylation pattern, imprinting and other genetic machineries) can aid to better understand the inheritance of schizophrenia. 


\section{Stress}

In individuals with predisposition to psychosis and inadequate social support, stress may be a trigger factor [100]; moreover, a relationship between environmental stressors and seriousness psychotic symptoms has been described.

Since the $70^{\text {th }}$, in long-term outcome studies of schizophrenia, Bleuler [101], Harding et al [102], Ciompi [103] and others reported that a majority of patients may recover. Ciompi proposed a complex bio-psycho-social view of schizophrenia [104] based upon the vulnerability-stress model [105]. According to this model, certain preexisting, enduring vulnerability characteristics of the individual interact with stressful stimuli to produce transient intermediate states of processing capacity overload, autonomic hyper arousal, and impaired processing of social stimuli, before the onset of psychosis. These intermediate states increase the level and the frequency of the environmental stressors by causing breaking off in the patient's family and social environment. The feedback loop leads to more extreme processing capacity overload, autonomic hyper arousal, and deficit on processing social stimuli, until the individual's threshold point for the development of psychotic symptoms [106]. Stressful life events, that are independent of the direct effects of the disorder, may play a precipitating role in the onset of, at least, some acute psychotic episodes. Increased numbers of such events are founded to be present in the 3 to 5 weeks before psychotic episode onset [107, 108].

Recently, it was supposed that a deregulation by the ventral subiculum of the hippocampus, determined by stress or drug abuse, may lead to an overdrive to the dopamine system, causing psychotic events [109, 110].

As in the case of drug abuse, stress could act as a risk factor in specific biologically vulnerable individuals. However, findings on stress do not add data for or against either the neurodevelopmental or the degenerative hypothesis.

\section{Family Milieu}

Many researches in $80^{\text {th }}$ have been directed to one of the stressor condition, a critical or emotional involved family climate, termed "high expressed emotion" in the early British study [111]. The findings of a Goldstein's longitudinal study [112] indicated a correlation between certain family stress factors and the subsequent probability of schizophrenia or related disorders in an offspring. Various studies had support the view that a negative affective climate in the family is predictive of relapse in a patient-relative in the short term $[113,114]$.

The "double link" theory hypothesizes that in families of schizophrenic patients anomalous communication pattern is presents. In such disturbed communication nothing is clearly declared, but a thing is affirmed and after denied or affirmed with words and denied by communicative not-verbal formalities.

A determinant role in breaking psychosis, particularly in symptomatic relapses, seems to play the emotional familiar climate [115]. After neuroleptic drugs introduction, the majority of psychiatric patients came back to live in their own social milieu. More symptomatic relapses were evident in these patients compared to subjects who did not live with their own families; in particular, families characterized by high emotional background seem to facilitate relapses [116].

Overall, these studies indicate that familiar milieu and altered social relationships can contribute to the progressive go on of the illness.

\section{COURSE}

\section{Onset}

In the classic long-term follow-up study of Ciompi, about $50 \%$ of schizophrenic persons had an acute onset, and $50 \%$ a long prodromal phase [103].

The historical study of Hafner suggests that the onset of negative symptoms tends to occur about five years before the initial psychotic episode, with onset of positive symptoms much closer to first hospitalization [117]. Many researchers of the past, as Kraepelin and Bleuler, have observed that schizophrenic individuals showed before the onset of illness a distinctive premorbid personality. Cutting [118] showed the presence of premorbid schizoid personality in $25 \%$ of schizophrenic individuals, and other personality disorders in almost 15\%. Another study [119] showed that $35 \%$ of schizophrenic individuals met DSM-IV diagnostic criteria for personality disorders during premorbid phase; $44 \%$ of them were represented by schizoid personality disorder. Premorbid explosive and paranoid traits are commoner in patients with schizophrenia than in patients with other nonorganic psychosis, and may shape the expression of symptoms during an illness episode [120]. A more recent longitudinal study [121] of an unselected general community population showed that "paranoid-schizotypal" traits was significantly associated with subsequent onset of both nonaffective and affective psychosis; when schizophrenia was analyzed separately, these traits did not remained significant.

Epidemiological literature, since few years ago, has reported a peak of onset in males between 15 and 25 years of age and for females between 25 and 35 years of age, with a strong difference in sex ratio starting at 15 years of age. Yet, it's difficult to compare the data mentioned above with the last researches, due to the selection of the cohort subjects using different diagnostic criteria in comparison with the present criteria.

More recent studies confirm difference of onset in both sexes, but in males the peak is delayed about 2 years from what was previously though.

The recent meta-analysis on previous studies seems to confirm that the peak in males is before that in females, but it is later than previously believed [122].

Crow [123] starting from epidemiological data regarding sex difference in age of onset of schizophrenia, premorbid precursors and outcome, proposed an evolutionary mechanism of sexual selection acting to retain different ranges of variation of the $\mathrm{Xq} 21.3 / \mathrm{Yp} 11.2$ homology block that was established by an $\mathrm{X}$ to $\mathrm{Y}$ duplication 6 million years ago. This duplication and its subsequent modification on the $Y$ may have played a central role in the evolution of the language, distinguishing the Homo sapiens from its precursors. The expression of genes within the homologous region is influenced by the extent to which the $\mathrm{X}$ and $\mathrm{Y}$ chromosomes 
pair during male meiosis, and this mechanism generates epigenetic diversity relating to the species capacity for language, but it may been related to a genetic predisposition to psychosis. Moreover, the same author and colleagues [124] proposed that this gene could be the principal determinant of the brain growth, explaining the anomalies of brain development (i.e. ventricular enlargement, reduction of total cortical mass and loss of asymmetry) reported in adolescents with diagnosis of schizophrenia.

All together, the core of researches reporting differences in gender and age at onset seem to point towards a role of precocious neurobiological determinants in the onset of the disease.

\section{Course and Outcome}

In Ciompi's classic study [103] about half of schizophrenic patients had an undulating course, with partial or full remissions followed by recurrences, in an unpredictable pattern. About one-third had relatively chronic, unremitting course with poor outcome. In that study a minority of patients had a steady pattern of recovery with good outcome.

Follow-up studies, which are not strictly prospective, such as the Ciompi's one, can be deceptive, because there is a tendency to focus on residue of chronic cases, making the disorder to appear more chronic than it actually is.

Studies on discharge indicated that about $20 \%$ of patients don't require re-admission, many years after discharge. Between these studies, the Danish one [125] is particularly interesting because the sample size and the long follow-up. Following the first discharge, $20 \%$ of the surviving patients had not been readmitted after 10 years of follow-up. Readmission risk increased with the number of previous admissions. At the first discharge, readmission risk decreased with increasing age and it was significantly predicted by clinical subtype and gender. Effect of these variables gradually disappeared at later discharges. At the 15 th discharge, readmissions were mainly predicted by duration of the latest admission and discharge periods. Data supported the existence of a smaller subpopulation among schizophrenic patients with frequent relapses.

Females show good course and outcome compared to males: collected data indicate lower proportion of females remaining with psychotic symptoms over time from onset compared to males.

A hypothesis of a possible role of estrogen or, more in general, of neuro-active steroids was suggested, both concerning course and outcome and age at onset [126, 127], but no systematic studies were carried out on this topic.

A not alternative hypothesis is that the different age at onset (earlier for males) may influence the course.

It may also be true that social outcome differs by sex. For example, percentage of married females is higher than married males.

There is variation in course of schizophrenia around the world, with better prognosis in so-called "developing" Countries. A summary of data from the WHO study on this issue shows that individuals with schizophrenia in developing Countries are less likely to have been chronically psychotic over the period of follow-up and more likely to have no residual symptoms after five years [128].This result remains to be explained. It could be that individuals meeting criteria for schizophrenia in developing countries include a subset destined for better prognosis because of the risk factor structured in those countries- more deaths of compromised fetuses, for example- or cause connected to good prognosis, such as a parasite psychosis like schizophrenia which is rare in developed countries. Another interpretation is that the environment of recovery in developed world is more pernicious, involving harsher economic competition, greater degree of stigma and smaller family networks who can share the burden of care for persons with schizophrenia [129]. Moreover, also skills requested in developing countries may differ.

\section{Course and Progressive Hypothetical Cognitive Deficit}

Many psychiatrists believe that the course of schizophrenia evolves toward cognitive deficit or, at least, to residual symptoms.

Emil Kraepelin (1856/1926) was the first to suppose an "organic" nature of schizophrenia, and he also suggested that core feature of the illness is the cognitive impairment, so he defined schizophrenia dementia praecox, and characterized it as dysfunction in what today we call "executive function", such volition and will.

Although this promising beginning, in the first half and in the early second half of $20^{\text {th }}$ century the interest of researchers focused on effort to demonstrate a psychogenic cause of schizophrenia, with results sometimes at least debatable. Even in $1960^{\text {th }}$, some researchers interpreted deficit performance in neuropsychological tests by schizophrenic patients as weakness correlated with psychotic symptoms and social problems, rather than reflecting true neurocognitive impairment.

Finally, in the last quarter of $20^{\text {th }}$ century, although role of psychosocial stressors was still recognized, the researchers accepted the fact that schizophrenia is fundamentally a brain disorder, and that it is characterized to diffuse neurocognitive deficits toward most cognitive domains.

Literature on course of schizophrenia seems to produce evidences that a percentage of patients with schizophrenia may have a good outcome, so this literature seems to indirectly refute concept of a progressive, ineluctable cognitive impairment in schizophrenia. In fact, while cognitive impairment is present in most, if not all, schizophrenic patients, there is both inter-patient heterogeneity and within-patient stability of cognitive function over the long-term course of the illness. Neuropsychological studies in the recent past established the primacy of cognitive functions over psychopathological symptoms as determinants of functional outcome and independence in everyday skills.

In a paper published by the group of Dumfries University, Morrison and colleagues [130] say that cognitive impairment can be found in the majority of patients with schizophrenia and it is a strong predictor of eventual social and functional outcome, but the published researches examining long-term course of impairment are inconsistent. Cross-sectional studies provided evidences both for and 
against progressive deterioration, but these studies are vulnerable to cohort effects producing differences not due to within-individual changes. More recently, well-designed longitudinal studies again produced conflicting results with some supporting the notion of progressive decline and others refuting it.

Morrison and colleagues [130] examined course of schizophrenic cognitive impairment over a period of, on average, 33 years. Participants with schizophrenia were found to show impairment in verbal and non-verbal intelligence at baseline compared with estimated premorbid scores, not found in control group. At follow-up there was a significant decline in non-verbal intelligence over time in participants with schizophrenia compared with controls. This differential change over time was not seen in verbal intelligence. This is in direct contradiction with the longitudinal studies of Gold [131] and Hoff [132] but it is in agreement with a more recent 10 -years study showing progressive visual-spatial impairment [133]. These results also suggest that cognitive decline is not global, not resembling a true dementia, but instead affects specific areas of cognition and may thus reflect pathological changes in certain areas of the brain or brain systems involved in visual-spatial problem solving and fluid components of intelligence, as showed by administering visual-spatial processing test [134].

A recent address of research is focused to establish if cognitive impairment in schizophrenia is present in childhood and if it remains stable in adulthood (developmental deficit hypothesis), or if children who develop schizophrenia in adulthood fall behind their peers (developmental lag hypothesis), or even if they have a cognitive decline only immediately before the onset of the disease or as a result of the same (neurodegenerative hypothesis). Apparently, the first hypothesis seems to be more possible than the second and the third one, as confirmed by a vast amount of evidences.

In a recent cohort study [135], Reichenberg and colleagues have evidenced that those children who develop schizophrenia in adulthood showed cognitive impairments that rose early and remained stable. Those deficits concern acquisition of verbal and visual-spatial capacities on tests processing, reasoning and conceptualizing skills; moreover, those children show a lag regard processing speed, attention, problem solving on visual-spatial problems and regard working memory.

Results of two meta-analytic reviews of studies documenting pre-morbid IQ among persons who subsequently developed schizophrenia suggest the presence of at least a mild pre-morbid cognitive deficit, with an average score of 90 to 95 . But there was no evidence of age-related decline in IQ during pre-morbid period and there was no difference in the pattern of intellectual skills when considered in terms of Verbal versus Performance IQ [136, 137].

Seidman and colleagues examined changes in IQ of persons with schizophrenia when they were aged 7 years-old and again about 28 years later in Seidman and colleagues examined changes in IQ of person with schizophrenia when they were 7 years-old and again about 28 years later. The researchers showed that persons who developed schizophrenia had lower QI scores when tested as children relatively to non-schizophrenic peers; moreover, schizophrenic patients showed decline of, on average, 10 QI points [138].

Contrary to Kraepelin's suggestion that dementia praecox is characterized by a progressive decline in neurocognitive function, longitudinal and cross-sectional studies of noninstitutionalized outpatients with schizophrenia demonstrate stable cognitive deficits after illness onset [139-141]. A possible exception to evidence of stability of cognitive functions in schizophrenia may be considered the case of older schizophrenic patients with a long-time experience of institutionalization [142, 143]. It has long been suggested that there may be a subgroup of patients with schizophrenia, who show a progressively deteriorating course conforming to the Kraepelin's views, termed "Kraepelinian". The Kraepelinian patients are characterized by severe dysfunctions in self-care $[144,145]$, disturbance in premorbid sociosexual functioning [146], more severe negative symptoms and formal though disorder [147], lower association with affective symptoms [148], extensive family history of schizophrenia spectrum disorders [145], resistance to antipsychotic treatments [144], early age of onset [149]. Decline in overall cognitive functions in those patients seems in fact greater than that which can be attributed to normal aging and it doesn't seem to be attributable to a co-morbid neurodegenerative disease [150]. However, it appears difficult to establish if neurocognitive impairment in long-term institutionalized schizophrenic patients is a featured entity or if it is due to the chronic institutionalization itself. A recent longitudinal study [151] examined a sample of schizophrenic older outpatients that experienced a history of long-term institutionalization, to address the question of environmental role influence or patient individual features regarding neurocognitive impairment and functional outcome. This research suggests that people with schizophrenia with history of institutional stay show evidence of differential declines in ability to perform everyday living skills over 3 to 4 years follow-up period, but cognitive performance did not show evidence of either decline in previously institutionalized outpatients or improvement in individuals without history of institutionalization.

One of the myths regarding cognitive impairment of schizophrenia individuals is the cognitive benefits of second generation antipsychotic medications in comparison with conventional neuroleptics. The most important investigation on cognitive effect of antipsychotic medications was provided by the NIMH-sponsored Clinical Antipsychotic Trials of Intervention Effectiveness (CATIE) schizophrenia study [152]. The CATIE Trial analyzed the cognitive effectiveness of antipsychotic drugs, both conventional neuroleptic (perphenazina) and second generation antipsychotics (olanzapine, quetiapine, risperidone and ziprasidone). There was a significant improvement in cognitive performances within each of the treatment groups, without significant differences in terms of change in any specific cognitive domains. Nevertheless, group treated with conventional neuroleptic showed unexpected greater improvement of cognitive performances than did those randomized to second generation antipsychotics.

As mentioned above, not all patients with schizophrenia show cognitive impairment, and they appear to be neuropsychologically normal. Most of neuropsychological researches 
about neurocognitive impairment in schizophrenia show a significant but modest association between severity of cognitive deficits and negative symptoms, and none association between cognitive deficits and positive symptoms [153]. Moreover, neuropsychologically normal schizophrenic patients, relative to neuropsychologically impaired ones, show significantly less negative symptoms and extrapyramidal symptoms, have more frequent social contacts, and are less likely to have had no psychiatric hospitalization in year preceding evaluation [154]. The neuropsychologically impaired patients also have worse mean scores on global assessment of psychosocial functioning, lower proportion of paranoid subtype, earlier age of onset and longer duration of disease [155]. Furthermore, a recent research focusing on difference between neuropsychologically normal versus neuropsychologically impaired schizophrenia groups, in reference of functional status, shows no difference in severity of psychopathology, but neuropsychologically normal patients have better scores on measure of social competence and functional capacity and they are more likely to have independent status [156-158].

\section{Course and Treatment with Regard of Cognitive Impairment}

Although the cognitive benefits of both conventional and even second generation antipsychotic drugs appear marginal, recognition of the importance of cognitive impairment as determinant of outcome in schizophrenia has focused actual efforts to develop targeted treatments for it. There are a growing number of studies showing that deficits in elementary neurocognitive function explain $20-60 \%$ of variance studies of ability to solve interpersonal problems, social function and measures of skill acquisition in rehabilitation programs, and cognitive deficits are more closely linked to functional outcome than are psychiatric symptoms.

Neurocognitive impairment in schizophrenia patients is treated with cognitive remediation, rehabilitation programs derived from cognitive-behavioral therapy methods, focused on improvement on vigilance and attention deficit, working memory capability, verbal and non-verbal learning memory, processing speed and language. A recent meta-analytic research [159] shows durable effects on global cognition and functioning, while symptoms improvement is small and transient. According to other two meta-analysis [160, 161], the effect of cognitive remediation is emphasized when it is combined with other psychiatric rehabilitation to improving functional outcomes.

While cognitive outcome of treatment is not associated to the methodology adopted (i.e. computer use, duration, type of approach, etc.), it seems to be connected with age, longterm illness and cognitive resources. A recent study [162] indicates that a broad cortical surface area and grey matter reserve is associated with accelerate social-cognitive responses to Cognitive Enhancement Therapy in earlier patients, while patients with less neurobiologic reserve obtain benefits of cognitive rehabilitation after a long treatment duration.

Many studies considered social cognition abilities as a target of rehabilitation interventions, according to the hypothesis that cognitive remediation would improve both cognitive and psycho-social outcomes. In reference to this, a large number of interventions are focused on social skills enhancement. Those rehabilitation approaches are generally based on psychoeducation and share many cognitivebehavioral tools; differences regard target symptom or problem that is attacked. Recently, a research [163] compared two of the rehabilitation therapies focusing on the improvement of neurocognitive and psychosocial outcomes, the Problem Solving Training and the Cognitive-Emotional Rehabilitation, showing that both approaches, based on structured methods to develop solutions to everyday life problems assigning at patient a central role of responsibility, should be effectives.

Vocational rehabilitation program utilizes work to improve symptoms, interpersonal relationships and cognitive functioning. A recent research [164] shows that vocational rehabilitation can improve negative and positive symptoms, though disturbances and paranoid ideation, contributing to enhance cognitive functions. Vocational rehabilitation required fewer economic and human resources to be applied, so it is useful method also in developing countries [164, 165]. Moreover, ability to obtain and to keep employment may help schizophrenic people to avoid stigmatization and auto-stigmatization that lead to emotional stress reaction and cognitive coping responses associated with social cognitive deficits [166].

\section{Role of Neuroimaging}

Neuroimaging is an emergent tool in study of schizophrenia. Many studies start from proposition that schizophrenia arises as a consequence of both an "early developmental" disturbance, as well as "late developmental" changes. The most consistently replicated structural anomaly in brain of chronic schizophrenia individuals is ventricular enlargement, medial temporal lobe structures (i.e. amygdala, hippocampus, and para-hippocampal gyrus) and superior temporal gyrus abnormalities.

In favor of the early developmental changes thesis, longitudinal magnetic resonance imaging (MRI) findings in the ultra-high risk cohort of Melbourne showed excessive neuroanatomical changes in those who convert to psychosis, most prominently in medial temporal and prefrontal regions, indicating an accelerated loss of grey matter in patients compared to healthy controls [167]. Expansion of the ventricular system is particularly pronounced in patients with very poor outcome, and it was been proposed specific to this patient group, associate with cognitive deficits and progressive [168].

Volumetric study of grey matter in subjects with 22q11.2 deletion syndrome and schizophrenia showed a significant grey matter reduction in the Brodmann's area 22, again supporting a neurodevelopmental model of schizophrenia [169]. Studies that apply functional MRI (fMRI) [170] have helped to elucidate potential neural substrates of schizophrenia. Some studies assumed that signs and symptoms of the disease are due to a disordered circuitry within a critical brain region, while other assumed that a disordered connection between brain regions may explain the clinical characteristics of the schizophrenia. Data from functional brain imaging support both the hypotheses [171]. 


\section{CONCLUSIONS}

History of epidemiology of schizophrenia results longdated and doubtful. Although a lot of steps forward are taken after the earlier studies carried out by Farris and Dunham, it doesn't exist an etiopathogenetic hypothesis shared between different schools of minds. Moreover, some of the consolidated beliefs are debated by later studies, i.e. data regarding prevalence of the disease or differences between sexes. New risk factors are considered, but the true association with schizophrenia is still uncertain. It cannot be definitively concluded for or against the neurodevelopmental or degenerative hypothesis, but efforts in understanding basis of schizophrenia must goes on. Indeed, to obtain firm data for or against one of the two hypotheses, or both, is not without relevance in planning treatments for schizophrenia patients. So, next efforts should be focused on getting ready a multifactorial etiopathogenetic model, considering the recent headways of medical genetics. Furthermore, a better knowledge of risk factors and their relative weights in the risk formulation could raise its positive predictive value in prevention and in the treatment of schizophrenia. It could also be useful in increasing the efficacy of first episode treatment aiming to limit the catastrophic effects that first episode could have to the functioning of people with schizophrenia. It seems that the majority of findings from the most recent researches confirmed the idea that schizophrenia arises in primis from a neurodevelopmental disorder and that subsequent symptomatology may be ameliorated using early survey in high risk subjects and precocious treatments in persons who manifested signs and symptoms of the disease. The neurodevelopmental hypothesis also appears the most convincing regard cognitive impairment in schizophrenia, and many researches demonstrated that schizophrenia is not a dementia praecox: in fact, cognitive deficits are stable in the course of illness, and they should improve thanks to cognitive remediation approaches.

Until now, rehabilitation programs move from the vulnerability-stress model. This model may be well adapted to the findings that proved the neurodevelopmental hypothesis: in fact, supposing an early deficit that go on stable during the life under favorable circumstances, it's possible think to rehabilitation models could influence functioning providing people with schizophrenia with integrate and complex strategies (as neuro-cognitive approaches, social skill training, cognitive-emotional training). This kind of intervention acts on the individual and micro-group coping skills, helping to resist to the environmental stress factors.

However, multiple cognitive impairments may represent important causes of psychosocial impairment, stigmatization, poor outcome in schizophrenic patients and, in a general sense, could have a negative impact on functioning in different daily life activities and life domains (social, vocational, and so on). So, cognitive deficits may represent target of randomized trials about neuropsychological rehabilitation in people with schizophrenia and, in general, the starting-point for further researches on schizophrenia. Cohort studies are necessary to defined the range of effectiveness and the outcome of single treatment or mixed treatments based on integration between different kind of rehabilitation approaches (devoted to people with schizophrenia and their families or social worlds) and to measure their influences in real life functioning and on the remediableness of schizophrenic cognitive deficits.

\section{FINANCIAL SUPPORT}

This review was conducted with the financial support of the Italian Medicines Agency (Agenzia Italia del Farmaco) grant for SPERA-S Study on Psychoeducation Enhancing Results of Adherence in Schizophrenia (FARM892ZXE).

\section{CONFLICT OF INTEREST}

None declared.

\section{ACKNOWLEDGEMENT}

None declared.

\section{REFERENCES}

[1] Cooper JE, Kendall RE, Gurland BJ, et al. Psychiatric diagnosis in New York and London: A comparative study of mental hospital admissions. Institute of Psychiatry, Maudsley Monographs, No 20. London, UK: Oxford University Press 1972.

[2] Wing JK, Birley JLT, Cooper JE, et al. Reliability of a procedure for measuring and classifying "present psychiatric state". Br J Psychiatry 1967; 113: 499-515.

[3] Feighner JP, Robins F, Guze SB, et al. Diagnostic criteria for use in psychiatric research. Arch Gen Psychiatry 1972; 26: 57-63.

[4] Wing J, Nixon J. Discriminating symptoms in schizophrenia. A report from the international pilot study of schizophrenia. Arch Gen Psychiatry 1975; 32(7): 853-9.

[5] Sartorius N, Jablensky A, Korten A, et al. Early manifestations and first-contact incidence of schizophrenia in different cultures. A preliminary report on the initial evaluation phase of the WHO Collaborative Study on determinants of outcome of severe mental disorders. Psychol Med 1986; 16(4): 909-28.

[6] Jablensky A, Sartorius N, Ernberg G, et al. Schizophrenia: Manifestation, incidence and course in different cultures. A World Health Organization ten-country study. Psychol Med Monogr Suppl 1992; 20: 1-97.

[7] Saha S, Chant D, Welham J, McGrath J. A systematic review of the prevalence of schizophrenia. PLoS Med 2005; 2(5): e141 .

[6] Jablensky A, Sartorius N, Ernberg G, et al. Schizophrenia: Manifestation, incidence and course in different cultures. A World Health Organization ten-country study. Psychol Med Monogr Suppl 1992; 20: 1-97.

[8] McGrath J, Saha S, Welham J, et al. A systematic review of the incidence of schizophrenia: The distribution of rates and the influence of sex, urbanicity, migrant status and methodology. BMC Med 2004; 2:13.

[9] Aleman A, Kahn RS, Selten JP. Sex differences in the risk of schizophrenia: Evidence from meta-analysis. Arch Gen Psychiatry 2003; 60: 565-71.

[10] Andreasen NC, Nasrallah HA, Dunn V, et al. Structural abnormalities in the frontal system in schizophrenia: a magnetic resonance imaging study. Arch Gen Psychiatry 1986; 43: 136-44.

[11] Feinberg I. Schizophrenia and late maturational brain changes in man. Psychopharmacol Bull 1982; 18: 229-31.

[12] Weinberger DR. Implications of normal brain development for the pathogenesis of schizophrenia. Arch Gen Psychiatry 1987; 44: 660-9.

[13] Torrey EF, Miller J, Rawlings R, Yolken RH. Seasonality of births in schizophrenia and bipolar disorders: a review of the literature. Schizophr Res 1997; 28: 1-38.

[14] Carriòn-Baralt JR, Fuentes-Rivera Z, Schmeidler J, Silverman JM. A case-control study of the seasonality effects on schizophrenic births on a tropical island. Schizophr Res 2004; 71(1): 145-53.

[15] Ellman LM, Yolken RH, Buka SL, Torrey EF, Cannon TD. Cognitive functioning prior to the onset of psychosis: the role of fetal exposure to serologically determined influenza infection. Biol Psychiatry 2009; 65(12): 1040-7. 
[16] Cannon M, Jones PB, Murray RM. Obstetric complications and schizophrenia: historical and meta-analytic review. Am J Psychiatry 2002; 159: 1080-92.

[17] Byrne M, Agerbo E, Bennedsen B, Eaton WW, Mortensen PB. Obstetric conditions and risk of first admission with schizophrenia: a Danish national register based study. Schizophr Res 2007; 97: 519 .

[18] Zammit S, Odd D, Horwood J, et al. Investigating whether adverse prenatal and perinatal events are associated with non-clinical psychotic symptoms at age 12 years in the ALSPAC birth cohort. Psychol Med 2009; 39: 1457-67.

[19] Yolken RH, Bachmann S, Rouslanova I, et al. Antibodies to Toxoplasma gondii in individuals with first-episode schizophrenia. Clin Infec Dis 2001; 32:842-4.

[20] Yolken RH, Dickerson FB, Fuller Torrey E. Toxoplasma and schizophrenia. Parasite Immunol 2009; 31(11): 706-15.

[21] Henriquez SA, Brett R, Alexander J, Pratt J, Roberts CW. Neuropsychiatric disease and Toxoplasma gondii infection. Neuroimmnomodulation 2009; 16(2): 122-33.

[22] da Silva RC, Langoni H. Toxoplasma gondii: host-parasite interaction and behavior manipulation. Parasitol Res 2009; 105(4): 893-8.

[23] Niemi LT, Suvisaari JM, Tuulio-Henriksson A, Lonnqvist JK. Childhood developmental abnormalities in schizophrenia: evidence from high-risk studies. Schizophr Res 2003; 60(2-3): 239-58.

[24] Reichenberg A, Caspi A, Harrington H, et al. Static and dynamic deficits in childhood preceding adult schizophrenia: a 30-year study. Am J Psychiatry 2010; 167(2): 160-9.

[25] Gregory I. An analysis of family data on 1000 patients admitted to a Canadian mental hospital. Acta Genet Stat Med 1959; 9: 54-96.

[26] Petersen L, Mortensen PB, Pedersen CB. Paternal age at birth of first child and risk of schizophrenia. Am J Psychiatry 2011; 168(1): 82-8.

[27] Perrin M, Harlap S, Kleinhaus K, et al. Older paternal age strongly increases the morbidity for schizophrenia in sisters of affected females. Am J Med Genet B Neuropsychiatr Genet 2010; 153B(7): 1329-35.

[28] Li X, Sundquist J, Sundquist K. Age-specific familial risk of psychotic disorders and schizophrenia: a nation-wide epidemiological study from Sweden. Schizophr Res 2007; 97(1-3): 43-50.

[29] Hubert A, Szoke A, Leboyer M, Schurhoff F. Influence of paternal age in schizophrenia. Encephale 2011; 37(3): 199-206.

[30] Torrey EF, Buka S, Cannon TD, et al. Paternal age as a risk factor for schizophrenia: how important is it? Schizophr Res 2009; 114 (1-3): $1-5$.

[31] Malaspina D, Harlap S, Fenning S, et al. Advancing paternal age and the risk of schizophrenia. Arch Gen Psychiatry 2001; 58:361.

[32] Sipos A, Rasmussen F, Harrison G, et al. Paternal age and schizophrenia: a population based cohort study. BMJ 2004; 329 (7474): 1070.

[33] Perrin MC, Brown AS, Malaspina D. Aberrant epigenetic regulation could explain the relationship of paternal age to schizophrenia. Schizophr Bull 2007; 33:1270-3.

[34] Lee H, Malaspina D, Ahn H, et al. Paternal age related schizophrenia (PARS): Latent subgroups detected by K-means clustering analysis. Schizophr Res 2011; 128(1-3): 143-9.

[35] Torrey EF, Yolken RH. The schizophrenia-rheumatoid arthritis connection: infection, immune, or both? Brain Behav Immun 2001; 15(4): 401-10.

[36] Othman SS, Abdul Kadir K, Hassan J, et al. High prevalence of thyroid function test abnormalities in chronic schizophrenia. Aust N Z J Psychiatry 1994; 28(4): 620-4.

[37] Hardoy MC, Cadeddu M, Serra A, et al. A pattern of cerebral perfusion anomalies between major depressive disorder and Hashimoto thyroiditis. BMC Psychiatry 2011; 11(1): 148.

[38] Eaton WW, Byrne M, Ewald H, et al. Association of schizophrenia and autoimmune diseases: linkage of Danish national registers. Am J Psychiatry 2006; 163(3): 521-8.

[39] Kalaydjian AE, Eaton W, Cascella N, Fasano A. The gluten connection: the association between schizophrenia and celiac disease. Acta Psychiatr Scand 2006; 113: 82-90.

[40] Schmitt A, Leonardi-Essmann F, Durrenberger PF, et al. Regulation of immune-modulatory genes in left superior temporal cortex of schizophrenia patients: a genome-wide microarray study. World J Biol Psychiatry 2011; 12: 201-15.

[41] Odegaard O. Emigration and insanity. Acta Psychiatr Neurol Scand Suppl 1932; 4:1-206.
[42] Carta MG, Bernal M, Hardoy MC, Haro-Abad JM, and the "Report on Mental Health in Europe" working group. Migration and mental health in Europe (the state of the mental health in Europe working group: appendix 1). Clin Pract Epidemiol Ment Health 2005; 1: 13.

[43] Murray RM, Hutchinson G. Psychosis in migrants: the striking example of African-Carribean resident in England: In Gattaz WF, Hafner H, Eds.Search for the causes of Schizophrenia vol 4: Balance of the Century. Darmastadt, Germany: Steinkopff/Springer 1999; pp. 129-140.

[44] Selten JP, Veen N, Feller W, et al. Incidence of psychotic disorders in immigrant groups to the Netherlands. Br J Psychiatry 2003; 182: $117-22$.

[45] Selten JP, Slaets JP, Kahn RS. Schizophrenia in Surinamese and Dutch Antillean immigrants in the Netherlands: evidence of an increased incidence. Psychol Med 1997; 27: 807-11.

[46] Cantor-Graae E, Pedersen CB, McNeil TF, Mortensen PB. Migration as a risk factor for schizophrenia: a Danish population-based cohort study. Br J Psychiatry 2003; 182: 117-22.

[47] Cooper B. Schizophrenia, social class and immigrant status: the epidemiological evidence. Epidemiol Psychiatr Soc 2005; 14: 137-44.

[48] Hjern A, Wicks S, Dalman C. Social adversity contributes to high morbidity in psychosis in immigrants-a national cohort study in two generation of Swedish residents. Psychol Med 2004; 34: 1025-33.

[49] Zolkowska K, Cantor-Grae E, McNeil TF. Increased rates of psychosis among immigrants to Sweden: is migration a risk factor for psychosis? Psychol Med 2001; 31: 669-78.

[50] Cochrane R, Bal SS. Migration and schizophrenia: an examination of five hypotheses. Soc Psychiatry 1987; 22: 181-91.

[51] Bourque F, van der Ven E, Malla A. A meta-analysis of the risk for psychotic disorders among first and second-generation immigrants. Psychol Med 2011; 41: 897-910.

[52] Cantor-Graae E, Selten JP. Schizophrenia and migration: A metaanalysis and review. Am J Psychiatry 2005; 162:12-24.

[53] Pedersen CB, Mortensen PB, Cantor-Graae E. Do risk factors for schizophrenia predispose to emigration? Schizophr Res 2011; 127: 229-34.

[54] van Os J, McGuffin P. Can the social environment cause schizophrenia? Br J Psychiatry 2003; 182: 291-2.

[55] Boydell J, van Os J, McKenzie K, et al. Incidence of schizophrenia in ethnic minorities in London: ecological study into interactions with environment. Br Med J 2001; 323: 1-4.

[56] Selten JP, Cantor-Graae E, Kahn RS. Migration and schizophrenia. Curr Opin Psychiatry. 2007; 20: 111-5.

[57] Fatemi SH, Folsom TD. The neurodevelopmental hypothesis of schizophrenia, revisited. Schizophr Bull 2009; 35: 528-48.

[58] Selten JP, Hoek HW. Does misdiagnosis explain the schizophrenia epidemic among immigrants from developing countries to Western Europe? Soc Psychiatry Psychiatr Epidemiol 2008; 43(12): 937-9.

[59] Haasen C, Yagdiran O, Mass R. Differences between psychopathological evaluation in German and Turkish language of Turkish immigrants. Nervenartz 2000; 71(11): 901-5.

[60] Casadio P, Fernandes C, Murray RM, Di Forti M. Cannabis use in young people: the risk for schizophrenia. Neurosci Biobehav Rev 2011; 35: 1779-87.

[61] Zammit S, Allebeck P, Andreasson S, Lundberg I, Lewis G. Selfreported cannabis use as a risk factor for schizophrenia in Swedish conscripts of 1969: historical cohort study. BMJ 2002; 325(7374): 1199.

[62] Dragt S, Nieman DH, Shultze-Lutter F, et al. Cannabis use and age of onset of symptoms in subjects at clinical high risk for psychosis. Acta Psychiatr Scand 2012; 125(1): 45-53.

[63] Swadi H, Bobier C. Substance use disorder comorbidity among inpatient youths with clinical disorder. Aust N Z J Psychiatry 2003; 37(3): 294-8

[64] Weiser M, Noy S. Interpreting the association between cannabis use and increased risk for schizophrenia. Dialogues Clin Neurosci 2005; 7(1): 81-5. Review.

[65] Costas J, Sanjùan J, Ramos-Rìos R, et al. Interaction between COMT haplotypes and cannabis in schizophrenia: a case-only study in two samples from Spain. Schizophr Res 2011; 127: 22-7.

[66] Farris RE, Dunham HW. Mental disorders in Urban Areas. Chicago: University of Chicago Press 1939.

[67] McGee R, Feehan M, Williams S, et al. DSM III disorders in a large sample of adolescents. J Am Acad Child Adolesc Psychiatry 1990; 29: 611-9. 
[68] Marcelis M, Takei N, van Os J. Urbanization and risk for schizophrenia: does the effect operate before or around the time of illness onset? Psychol Med 1999; 29(5): 1197-203.

[69] Pedersen CB, Mortensen PB. Evidence of a dose-response relationship between urbanicity during upbringing and schizophrenia risk. Arch Gen Psychiatry 2001; 58(11): 1039-46.

[70] Marcelis M, Navarro Mateu F, et al. Urbanization and psychosis: a study of 1942-1978 birth cohorts in the Netherlands. Psychol Med 1998; 28(4): 871-9.

[71] Haukka J, Suvisaari J, Varilo T, Lonnqvist J. Regional variation in the incidence of schizophrenia in Finland: a study of birth cohorts born from 1950 to 1969. Psychol Med 2001; 31(6): 1045-53.

[72] Mortensen PB. Why is the risk of schizophrenia greater in cities than in the country? Ugeskr Laeger 2001; 163: 4717-20.

[73] vanOs J, Pedersen CB, Mortensen PB. Confirmation of synergy between urbanicity and familial liability in the causation of psychosis. Am J Psychiatry 2004; 161 (12): 2312-4.

[74] Fox JW. Social class, mental illness, and social mobility: the social selection-drift hypothesis for serious mental illness. J Health Soc Behav 1990; 31: 344-53

[75] Jones PB, Bebbington P, Foerster A, et al. Premorbid social underachievement in schizophrenia. Results from the Camberwell Collaborative Psychosis Study. Br J Psychiatry 1993; 162: 65-71.

[76] Yang J, Visscher PM, Wray NR. Sporadic cases are the norm for complex disease. Eur J Hum Genet 2010; 18(9): 1039-43.

[77] Cardno AG, Gottesman I. Twin studies of schizophrenia: from bow-and-arrow concordance to Star Wars Mx and functional genomics. Am J Med Genet 2000; 97: 12

[78] Sullivan PF, Kendler KS, Neale MC. Schizophrenia as a complex trait: evidence from a meta-analysis of twins studies. Arch Gen Psychiatry 2003; 60(12): 1187-92.

[79] Gottesman II, Bertelsen A. Confirming unexpressed genotypes for schizophrenia. Risk in the offspring of Fischer's Danish identical and fraternal discordant twins. Arch Gen Psychiatry 1989; 46(10): 867-72.

[80] Kringlen E, Cramer G. Offspring of monozygotic twins discordant for schizophrenia. Arch Gen Psychiatry 1989; 46(10):873-7.

[81] Kendler KS, Gruenberg AM, Strauss JS. An independent analysis of the Copenhagen sample of the Danish adoption study of schizophrenia. II. The relationship between schizotypal personality disorder and schizophrenia. Arch Gen Psychiatry 1981; 38(9): 982-4.

[82] Itokawa M, Arinami T, Toru M. Advanced research on dopamine signalling to develop drugs for the treatment of mental disorders: Ser311Cys polymorphisms of the dopamine $\mathrm{D}_{2}$-receptor gene and schizophrenia. J Pharmacol Sci 2010; 114: 1-5.

[83] Williams HJ, Owen MJ, O'Donovan MC. Is COMT a susceptibility gene for schizophrenia? Schizophr Bull 2007; 33: 635-41.

[84] Bitsios P, Roussos P. Tolcapone, COMT polymorphisms and pharmacogenomic treatment of schizophrenia. Pharmacogenomics 2011; 12: 559-66.

[85] Costas J, Sanjuan J, Ramos-Rios R, et al. Interaction between COMT haplotypes and cannabis in schizophrenia: a case-only study in two samples from Spain. Schizophr Res 2011; 127: 22-7.

[86] Suarez BK, Duan J, Sanders AR, et al. Genomewide linkage scan of 409 European-ancestry and African American families with schizophrenia: suggestive evidence of linkage at 8p23.3-p21.2 and 11p13.1-q14.1 in the combined sample. Am J Hum Genet 2006; 78: 315-33.

[87] Faraone SV, Skol AD, Tsuang DW, et al. Genome scan of schizophrenia families in a large Veterans Affairs Cooperative Study sample: evidence for linkage to $18 \mathrm{p} 11.32$ and for racial heterogeneity on chromosomes 6 and 14. Am J Genet B Neuropsychiatr Genet 2005; 139B:91-100.

[88] Tabarés-Seisdedos R, Rubenstein JL. Chromosome 8p as a potential hub for developmental neuropsychiatric disorders: implications for schizophrenia, autism and cancer. Mol Psychiatry 2009; 14(6): 563-89.

[89] Mowry BJ, Holmans PA, Pulver AE, et al. Multicenter linkage study of schizophrenia loci on chromosome 22q. Mol Psychiatry 2004; 9(8): 784-95.

[90] Collins AL, Kim Y, Sklar P; International Schizophrenia Consortium, O’Donevan MC, Sullivan PF. Hypothesis-driven candidate genes for schizophrenia compared to genome-wide association studies. Psychol Med 2011; 19:1-9.

[91] International Schizophrenia Consortium. Purcell SM, Wray NR, Stone JL, et al. Common polygenic variation contributes to risk of schizophrenia and bipolar disorder. Nature 2009; 460 (7256): 74852.

[92] Rietschel M, Mattheisen M, Degenhardt F, et al. Association between genetic variation in a region on chromosome 11 and schizophrenia in large samples from Europe. Mol Psychiatry 2011 [Epub ahead of print].

[93] Greenwood TA, Lazzeroni LC, Murray SS, et al. Analysis of 94 candidate genes and 12 endophenotypes for schizophrenia from the Consortium on the Genetics of Schizophrenia. Am J Psychiatry 2011; 168(9): 930-46.

[94] Holmans PA, Riley B, Pulver AE, et al. Genomewide linkage scan of schizophrenia in a large multicentre pedigree sample using single nucleotide polymorphisms. Mol Psychiatry 2009; 14(8): 786-95.

[95] Fallin MD, Lasseter VK, Liu Y, et al. Linkage and association on 8p21.2-p21.1 in schizophrenia. Am J Med Genet B Neuropsychiatr Genet 2011; 156:188-97

[96] Levinson DF, Duan J, Oh S, et al. Copy number variants in schizophrenia: confirmation of five previous findings and new evidence for 3q29 microdeletions and VIPR2 duplications. Am J Psychiatry 2011; 168: 302-16.

[97] Ott J, Macciardi F, Shen Y, et al. A pilot study on schizophrenia in Sardinia. Hum Hered 2010; 70: 92-6.

[98] Stefansson H, Ophoff RA, Steinberg S, et al. Common variants conferring risk of schizophrenia. Nature 2009; 460: 744-7.

[99] O'Donovan MC, Craddock N, Norton N, et al. Identification of loci associated with schizophrenia by genome-wide association and follow-up. Nat Genet 2008; 40: 1053-5.

[100] Zubin J, Magaziner J, Steinhauer SR. The metamorphosis of schizophrenia: from chronicity to vulnerability. Psychol Med 1983; 13: 551-71

[101] Bleuler M. The schizophrenic disorders: long term patient and family studies. New Haven: Yale University Press 1978.

[102] Harding CM, Brooks GW, Ashikaga T, et al. The Vermont study of persons with severe mental illness. Long-term outcome of subjects who retrospectively met DSM-IV criteria for schizophrenia. Am J Psychiatry 1987; 144: 727-35

[103] Ciompi L. The natural history of schizophrenia in the long-term. $\mathrm{Br}$ J Psychiatry 1980; 136: 413-20.

[104] L. The dynamics of complex biological psychosocial systems-four fundamental psychobiological mediators in the long-term evolution of schizophrenia. Br J Psychiatry 1989; 155 (Suppl 5): 15-21.

[105] Zubin J, Spring B. Vulnerability- a new view of schizophrenia. J Abnorm Psychol 1977; 103-26.

[106] Neuechterlein KH, Dawson ME. A heuristic vulnerability/stress model of schizophrenia episodes. Schizophr Bull 1984; 10(2): 30012.

[107] Brown GW, Birley JL. Crises and life changes and the onset of schizophrenia. J Health Soc Behav 1968; 9: 203-14.

[108] Leff JP, Hirsch SR, Gaind R, Rohde PD, Stevens BS. Life events and maintenance therapy in schizophrenic relapse. Br J Psychiatry 1973; 123: 659-60.

[109] Grace AA. Dopamine system dysregulation by the ventral subiculum as the common pathophysiological basis for schizophrenia psychosis, psychostimulant abuse, and stress. Neurotox Res 2010; 18: $367-76$

[110] Corcoran C, Gallitano A, Leitman D, Malaspina D. The neurobiology of the stress cascade and its potential relevance for schizophrenia. J Psychiatr Pract 2001; 7: 3-14.

[111] Leff J, Vaughn C. Expressed emotion. Hosp Community Psychiatry $1987 ; 38(10): 1117-9$

[112] Goldstein MJ. Family factors that antedate the onset of schizophrenia and related disorders: the results of a fifteen year prospective longitudinal study. Acta Psychiatr Scand 1985; 71: 7-18.

[113] Goldstein MJ. Psychosocial issues. Schizophr Bull 1987; 13(1): 157-71

[114] Nuechterlein KH, Dawson ME, Ventura J, et al. The vulnerability/stress model of schizophrenic relapse: a longitudinal study. Acta Psychiatr Scand Suppl 1994; 382: 58-64.

[115] Meneghelli A, Alpi A, Pafumi N, et al. Expressed emotion in firstepisode schizophrenia and ultra high-risk patients: results from the Programma2000 (Milan, Italy). Psychiatry Res 2011; 189 (3): 3318.

[116] McCreadie RG, Robertson LJ, Hall DJ, Berry I. The Nithsdale schizophrenia survey. XI: Relatives'expressed emotion. Stability 
over five years and its relation to relapse. Br J Psychiatry 1993; 162: 393-7.

[117] Hafner H, Maurer K, Loffler W, et al. The epidemiology of early schizophrenia. Influence of age and gender on onset and early course. Br J Psychiatry Suppl 1994; 23: 29-38.

[118] Cutting J. The psychology of schizophrenia. London, UK.:Churchill Livingstone 1985.

[119] Pfohl B, Winokur G. The micropsychopathology of hebephrenic/catatonic schizophrenia. J Nerv Ment Dis 1983; 171:296300.

[120] Dalkin T, Murphy P, Glazebrook C, Medley I, Harrison G. Premorbid personality in first-onset psychosis. Br J Psychiatry 1994; 164(2): 202-7.

[121] Bogren M, Mattisson C, Tambs K, et al. Predictors of psychosis: a 50-year follow-up of the Lundby population. Eur Arch Psychiatry Clin Neurosci 2010; 260(2): 113-25.

[122] Aleman A, Kahn RS, Selten JP. Sex differences in the risk of schizophrenia: evidence from meta-analysis. Arch Gen Psychiatry 2003; 60(6): 565-71

[123] Crow TJ. The "big bang" theory of the origin of psychosis and the faculty of language. Schizophr Res 2008; 102(1-3): 31-52.

[124] James A, Crow YJ, Renowden S, et al. Is the course of brain development in schizophrenia delayed? Evidence from onsets I adolescence. Schizophr Res 1999; 40(1): 1-10.

[125] Bertelsen M, Jeppesen P, Petersen L, et al. Course of illness in a sample of 265 patients with first-episode psychosis-five-year follow-up of the Danish OPUS trial. Schizophr Res 2009; 107(2-3): 173-8.

[126] Riecher-Rossler A, Hafner H. Schizophrenia and oestrogens-is there an association? Eur Arch Psychiatry Clin Neurosci 1993; 242(6): 323-8

[127] Grigoriadis S, Seeman MV. The role of estrogen in schizophrenia: implications for schizophrenia practice guidelines for women. Can J Psychiatry 2002; 47(5): 437-42.

[128] Cohen A, Patel V. Questioning an axiom: better prognosis for schizophrenia in the developing world? Schizophr Bull 2008; 34(2): 229-44

[129] Alem A, Kebede D. Conducting psychiatric research in the developing world: Challenges and rewards. Br J Psychiatry 2003; 182: 185-7.

[130] Morrison G, O'Carroll R, McCreadie R. Long-term course of cognitive impairment in schizophrenia. Br J Psychiatry 2006; 189: 556-7.

[131] Gold S, Arndt S, Nopoulos P, O'Leary DS, Andreasen NC. Longitudinal study of cognitive function in first-episode and recent-onset schizophrenia. Am J Psychiatry 1999; 156(9): 1342-8.

[132] Hoff AL, Svetina C, Shields G, Stewart J, DeLisi LE. Ten year longitudinal study of neuropsycological functioning subsequent to a first episode of schizophrenia. Schizophr Res 2005; 78(1): 27-34.

[133] vanWinkel R, Myin-Germeys I, Delespaul P, et al. Premorbid IQ as a predictor for the course of IQ in first onset patients with schizophrenia: a 10-year follow-up study. Schizophr Res 2006; 88(1-3): 47-54.

[134] Hardoy MC, Carta MG, Catena M, et al. Impairment in visual and spatial perception in schizophrenia and delusional disorder. Psychiatry Res 2004; 127(1-2): 163-6.

[135] Reichenberg A, Caspi A, Harrington H, et al. Static and dynamic deficits in childhood preceding adult schizophrenia: a 30-year study. Am J Psychiatry 2010; 167(2): 160-9.

[136] Aylward E, Walker E, Bettes B. Intelligence in schizophrenia: meta-analysis of the research. Schizophr Bull 1984; 10: 430-59.

[137] Woodberry KA, Giuliano AJ, SeidmanLJ. Premorbid IQ in schizophrenia: a meta-analytic review. Am J Psychiatry 2008; 165: 57987.

[138] Seidman LJ, Buka SL, Goldstein JM, Tsuang MT. Intellectual decline in schizophrenia: evidence from a prospective birth cohort 28 years follow-up study. J Clin Exp Neuropsychol 2006; 28: 22542.

[139] Heaton RK, Gladsjo JA, Palmer BW, et al. The stability and course of neuropsychological deficits in schizophrenia. Arch Gen Psychiatry $2001 ; 58: 24-32$

[140] Rund BR. A review of longitudinal studies of cognitive functions in schizophrenia patients. Schizophr Bull 1998; 24: 425-35.

[141] Kurtz MM. Neurocognitive impairment across the lifespan in schizophrenia: an update. Schizophr Res 2005; 74: 15-26.
[142] White L, Friedman JI, Bowie CR, et al. Long term outcomes in chronically hospitalized geriatric patients with schizophrenia: retrospective comparison of first and second generation antipsychotics. Schizophr Res 2006; 88: 127-34.

[143] Rajji TK, Mulsant BH. Nature and course of cognitive functions in late-life schizophrenia: a systematic review. Schizophr Res 2008; 102: 122-140.

[144] Keefe RSE, Mohs RC, Losonczy MF, et al. Characteristics of very poor outcome schizophrenia. Am J Psychiat 1987; 144: 889-95.

[145] Keefe RSE, Freska E, Apter SH, et al. Clinical characteristics of Kraepelinian schizophrenia: Replication and extension of previous findings. Am J Psychiatry 1996; 153: 806-11.

[146] Keefe RSE, Mohs RC, Silverman JM, et al. Characteristics of Kraepelinian schizophrenia and their relation to premorbid sociosexual functioning. In: Angrist B, Schulz SC, Eds. The neuroleptic nonresponsive patients: Characterization and treatment. Washington DC: American Psychiatric Press 1990.

[147] Bralet MC, Loas G, Yon V, Marechal V. Clinical characteristics and risk factors for Kraepelinian subtype of schizophrenia: Replication of previous findings and relation to summer birth. Psychiatry Res 2002; 111: 147-54.

[148] Kilzieh N, Wood AE, Erdman J, Raskind M, Tapp A. Depression in Kraepelinian schizophrenia. Compr Psychiatry 2003; 44: 1-6.

[149] Brickman AM, Buchsbaum MS, Shihabuddin L, et al. Thalamus size and outcome in schizophrenia. Schizophr Res 2004; 71: 47384.

[150] Friedman JI, Harvey PD, Kemether E, Byne W, Davis KL. Cognitive and functional changes with aging in schizophrenia. Biol Psychiatry 1999 ; 46: 921-8.

[151] Harvey PD, Reichenberg A, Bowie CR, Patterson TC, Heaton RK. The course of neuropsychological performance and functional capacity in older patients with schizophrenia. Influences of previous history of long-term institutional stay. Biol Psychiat 2010; 67: 9339.

[152] Keefe R, Bilder RM, Davis SM, et al. Neurocognitive effects of antipsychotic medications in patients with chronic schizophrenia in the CATIE Trial. Arch Gen Psychiatry 2007; 64: 633-47.

[153] De GraciaDòminguez M, Viechtbauer W, Simons CJ, Van Os J, Krabbendam L. Are psychotic psychopathology and neurocognition orthogonal? A systematic review of their associations. Psychol Bull 2009; 135: 157-71.

[154] Palmer BW, Heaton RK, Paulsen JS, et al. Is it possible to be schizophrenic yet neuropsychologically normal? Neuropsychology 1997; 11: 437-46.

[155] Kremen WS, Seidman LJ, Faraone SV, Toomey R, Tsuang MT. The paradox of normal neuropsychological function in schizophrenia. J Abnorm Psychol 2000; 109: 743-52.

[156] Leung WW, Bowie CR, Harvey PD. Functional implication of neuropsychological normality and symptom remission in older outpatients diagnosed with schizophrenia: a cross-sectional study. J Int Neuropsychol Soc 2008; 14:479-88.

[157] Heinrichs RW, Miles AA, Smith D, et al. Cognitive, clinical, and functional characteristics of verbally superior schizophrenia patients. Neuropsychology 2008; 22: 321-8.

[158] Palmer BW, Heaton RK, Gladsjo JA, et al. Heterogeneity in functional status among older outpatients with schizophrenia: employment history, living situation, and driving. Schizophr Res 2002; 55: 205-15.

[159] Wykes T, Huddy V, Cellard C, McGurk SR, Czobor P. A metaanalysis of cognitive remediation for schizophrenia: methodology and effect sizes. Am J Psychiatry 2011; 168: 472-85.

[160] McGurk SR, Twamley EW, Sitzer DI, McHugo GJ, Mueser KT. A meta-analysis of cognitive remediation in schizophrenia. Am J Psychiatry 2007; 164: 1791-802.

[161] Kurtz MM, Moberg PJ, Gur RC, Gur RE. Approaches to cognitive remediation of neuropsychological deficits in schizophrenia: a review and meta-analysis. Neuropsychol Rev 2001; 11: 197-210.

[162] Keshavan MS, Eack SM, Wojtalik JA, et al. A broad cortical reserve accelerates response to cognitive enhancement therapy in early course schizophrenia. Schizophr Res 2011; 130:123-9.

[163] Veltro F, Mazza M, Vendittelli N, et al. A comparison of the effectiveness of Problem Solving Training and of Cognitive-Emotional Rehabilitation on neurocognition, social cognition and social functioning in people with schizophrenia. Clin Pract Epidemiol Ment Health $2011 ; 7: 123-32$. 
[164] Suresh Kumar PN. Impact of vocational rehabilitation on social functioning, cognitive functioning, and psychopathology in patients with chronic schizophrenia. Indian J Psychiatry 2008; 50: 257-61.

[165] Weng YZ, Xiang YQ, Liberman RP. Psychiatric rehabilitation in a Chinese psychiatric hospital. Psychiatr Serv 2005; 56: 401-3.

[166] Rusch N, Corrigan PW, Wassel A, et al. A stress coping model of mental illness stigma: I. Predictors of cognitive stress appraisal. Schizophr Res 2009; 110: 59-64.

[167] Pantelis C, Velakoulis D, Wood SJ, et al. Neuroimaging and emerging psychotic disorders: the Melbourne ultra-risk studies. Int Rev Psychiatry 2007; 19: 371-81.
[168] Mitelman SA, Buchsbaum MS. Very poor outcome schizophrenia: Clinical and neuroimaging aspects. Int Rev Psychiatry 2007; 19(4): 345-57.

[169] Chow EW, Ho A, Wei C, et al. Association of schizophrenia in $22 q 11.2$ deletion syndrome and grey matter volumetric deficits in the superior temporal gyrus. Am J Psychiatry 2011; 168: 522-9.

[170] Gur RE, Gur RC. Functional magnetic resonance imaging in schizophrenia. Dialogues Clin Neurosci 2010; 12: 333-43. Review.

[171] Brown GG, Thompson WK. Functional brain imaging in schizophrenia: selected results and methods. Curr Top Behav Neurosci 2010; 4: 181-214. Review.

Received: December 03, 2011

(c) Mura et al.; Licensee Bentham Open.

This is an open access article licensed under the terms of the Creative Commons Attribution Non-Commercial License (http://creativecommons.org/licenses/by-nc/3.0/) which permits unrestricted, non-commercial use, distribution and reproduction in any medium, provided the work is properly cited. 